\title{
Sporadic Jejunal Lateral Spreading Tumor: A Rare Cause of Recurrent Jejunojejunal Intussusception
}

\author{
Ana Ponte $^{\mathrm{a}}$ Rolando Pinho $^{\mathrm{a}}$ Adélia Rodrigues $^{\mathrm{a}}$ Amélia Tavares $^{\mathrm{b}}$ \\ Joana Ferreira $^{\mathrm{b}}$ Miguel Mendes $^{\mathrm{b}}$ Silvia Costa $^{\mathrm{b}}$ João Carvalho ${ }^{\mathrm{a}}$ \\ Departments of a Gastroenterology and ${ }^{b}$ General Surgery, Centro Hospitalar Vila Nova de Gaia/Espinho, \\ Vila Nova de Gaia, Portugal
}

\section{Keywords}

Deep enteroscopy · Lateral spreading tumor · Enteric invagination

\section{Lesão em tapete esporádica no jejuno: causa rara de invaginação jejunojejunal recorrente}

\section{Palavras Chave}

Enteroscopia profunda · lesão em tapete · invaginação entérica

A previously healthy 74-year-old woman with no relevant family medical history was referred to our department to investigate a jejunojejunal intussusception incidentally diagnosed in an abdominal ultrasound performed for evaluation of self-limited episodes of abdominal pain and vomiting. To further investigate the ultrasound findings, computed tomography (CT) was performed and revealed a target sign resulting from an extensive jejunojejunal invagination that involved a large

\begin{tabular}{|c|c|}
\hline KARGER & (C) 2016 Sociedade Portuguesa de Gastrenterologia \\
\hline 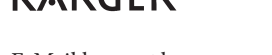 & Published by S. Karger AG, Basel \\
\hline www.karger.com/pjg & $\begin{array}{l}\text { This article is licensed under the Creative Commons Attribution- } \\
\text { NonCommercial-NoDerivatives } 4.0 \text { International License (CC BY- } \\
\text { NC-ND) (http://www.karger.com/Services/OpenAccessLicense). } \\
\text { Usage and distribution for commercial purposes as well as any dis- } \\
\text { tribution of modified material requires written permission. }\end{array}$ \\
\hline
\end{tabular}

edematous jejunal segment and mesenteric blood vessels and leading to proximal dilation of small-bowel loops with air-fluid levels inside (Fig. 1). Due to partial obstruction and absence of an underlying lesion identified on CT, the patient was referred to antegrade single balloon enteroscopy (Olympus SIF-Q180, Japan) that revealed a type 0 -IIa (Paris classification) granular lateral spreading tumor, measuring approximately $4 \mathrm{~cm}$ and occupying four fifths of the luminal circumference in the proximal jejunum (Fig. 2, 3). As endoscopic mucosal resection (EMR) was considered high risk, tattooing was performed and biopsy samples were obtained. Histology revealed a tubulovillous adenoma with low-grade dysplasia and foci of high-grade dysplasia. The patient underwent a laparoscopic enterectomy, whose histology confirmed the initial diagnosis. After surgery, the patient remained asymptomatic.

In adult intussusception there is an underlying cause in more than $90 \%$ of the cases, with tumors representing the most frequent etiology [1]. Benign and malignant small-bowel tumors are rare and account for approximately 3-6\% of all gastrointestinal neoplasms [2]. With the advent of capsule endoscopy and deep enteroscopy

\footnotetext{
Dr. Ana Ponte

Department of Gastroenterology, Centro Hospitalar Vila Nova de Gaia Rua Conceição Fernandes

PT-4434-502 Vila Nova de Gaia (Portugal)

E-Mail ana.ilponte@gmail.com
} 


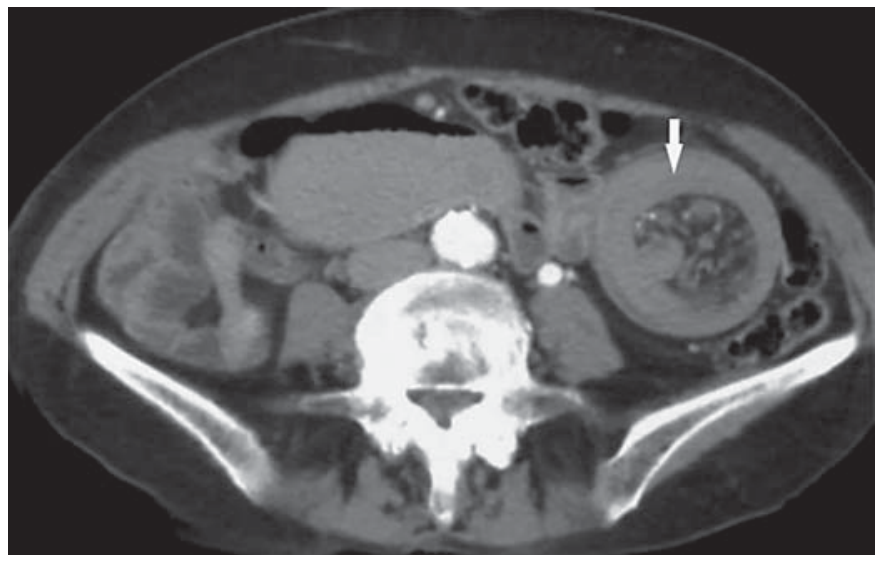

Fig. 1. Computed tomography image depicting a target sign secondary to a jejunojejunal invagination (arrow).

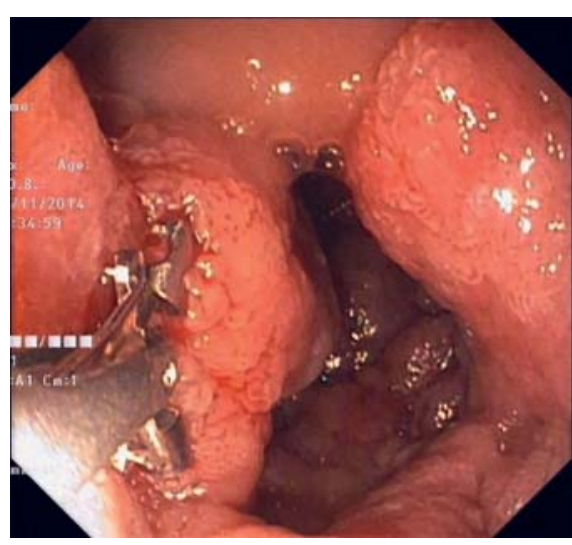

Fig. 3. Enteroscopy image showing a lateral spreading tumor in the jejunum.

(DE), the reported incidence of small-bowel tumors has increased [2]. Although it accurately identifies adult intussusception, CT may be unrevealing in the evaluation of incomplete small-bowel obstruction and small-bowel tumors $[1,3]$. In these cases, DE may provide additional diagnostic information [4]. Moreover, DE allows biopsy sampling and therapeutic interventions [2,3]. Removal of small-bowel adenomas is advisable due to their predisposition for malignancy.

The boundaries of therapeutic enteroscopy are being continuously expanded [4] and include nowadays smallbowel EMR, as described in a recent series [5]. In this case, EMR was considered high risk, given the longitudinal and

Sporadic Jejunal Lateral Spreading Tumor

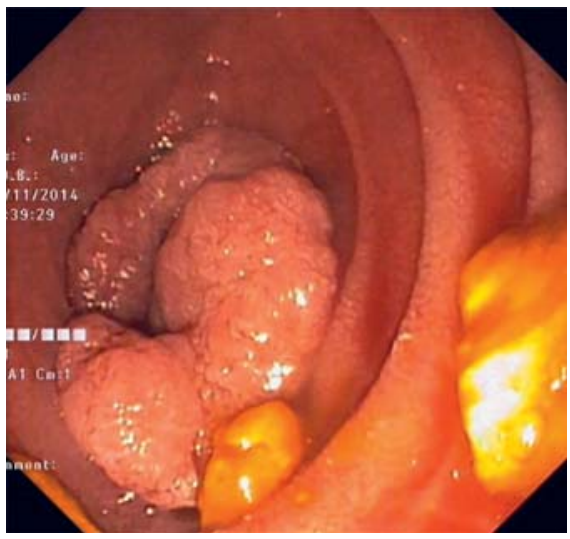

Fig. 2. Enteroscopy image showing a lateral spreading tumor in the jejunum.

circular extension of the lesion, which could be associated with a high rate of incomplete resection, perforation, or delayed stenosis. Hence, laparoscopic surgery was considered a safer therapeutic option.

\section{Statement of Ethics}

This study did not require informed consent nor review/approval by the appropriate ethics committee.

\section{Disclosure Statement}

The authors have nothing to disclose.

References

1 Honjo H, Mike M, Kusanagi H, Kano N: Adult intussusception: a retrospective review. World J Surg 2015;39:134-138.

2 Islam RS, Leighton JA, Pasha SF: Evaluation and management of small-bowel tumors in the era of deep enteroscopy. Gastrointest Endosc 2014;79:732-740

3 Sun B, Shen R, Cheng S, Zhang C, Zhong J: The role of double-balloon enteroscopy in diagnosis and management of incomplete small-bowel obstruction. Endoscopy 2007;39: 511-515.

4 Pinho R: The vanishing frontiers of therapeutic enteroscopy. GE Port J Gastroenterol 2015; 22:133-134.

5 Kröner PT, Sancar A, Fry LC, Neumann H, Mönkemüller K: Endoscopic mucosal resection of jejunal polyps using double-balloon enteroscopy. GE Port J Gastroenterol 2015; 22:137-142. 